\title{
PENGUKURAN TINGKAT KEMATANGAN LAYANAN PENGGUNA PERPUSTAKAAN ITS BERBASIS TEKNOLOGI INFORMASI (PERPUSTAKAAN ITS MENUJU WCUL)
}

\author{
Davi Wahyuni, Yeni Anita Gonti, Eva Mursidah, Adhatus Solichah \\ Institut Teknologi Sepuluh November, Surabaya \\ E-mail: yagyag73@gmail.com
}

\begin{abstract}
ABSTRAK
Tujuan dari penelitian ini adalah untuk menyusun usulan rekomendasi layanan perpustakaan di Institut Teknologi Sepuluh November Surabaya (ITS) yang berbasis teknologi informasi (TI) dengan menggunakan framework COBIT. COBIT merupakan sebuah panduan standar untuk praktik manajemen teknologi informasi. COBIT dapat membantu untuk menjembatani gap antara risiko-risiko bisnis, kebutuhan kontrol dan permasalahan-permasalahan teknis. Tingkat kematangan layanan pengguna perpustakaan ITS dianalisa berdasarkan faktor internal dan eksternal melalui wawancara dan penyebaran kuisioner. Indikator kepuasan pengguna diturunkan dengan menggunakan metode LibQual dan COBIT. Pada Libqual indikator kepuasan diturunkan dari pengukuran affect of service dan information control. Indikator kerja yang digunakan pada kerangka kerja COBIT adalah domain DS (delivery support). Selanjutnya hasil dari survey dan wawancara akan dibandingkan dengan kriteria World Class University Library (WCUL) untuk mengetahui kekurangan dari standar pelayanan perpustakaan yang diberikan di perpustakaan pusat ITS. Hasil dari penelitian yang dilakukan menunjukkan ITS memiliki nilai rata-rata tingkat kematangan 3 pada proses yang didefinisikan (defined process). Sedangkan berdasarkan kriteria WCUL, perpustakaan ITS memenuhi 4 item kriteria WCUL dari total 23 item kriteria. 19 item kriteria lainnya sudah diimplementasikan di perpustakaan ITS dengan nilai rata-rata yang hampir mendekati batas nilai untuk kriteria WCUL. Ada beberapa indikator yang digunakan sebagai objek prioritas usulan rekomendasi dalam penelitian ini, yaitu: Keselarasan Strategi (Strategic Alignment), Penyampaian Nilai (Value Delivery), Manajemen Sumber Daya (Resource Management), Manajemen Risiko (Risk Management), dan Pengukuran Kinerja (Performance Measurement). Luaran dari penelitian ini adalah berupa dokumen rekomendasi berdasarkan kelima indikator tersebut.
\end{abstract}

Kata kunci: LibQual, COBIT, world class university library, tingkat kematangan.

\section{PENDAHULUAN}

Pilar penting di perguruan tinggi adalah perpustakaan yang berperan sebagai penunjang utama kegiatan belajar mengajar dan penelitian. Juga berfungsi sebagai sumber pengetahuan dan informasi, lokasi belajar, pusat komunitas, tempat bertukar pengetahuan, melakukan preservasi dan pusat repository. Bila Perguruan tinggi menghendaki lulusannya merupakan bagian dari lulusan berstandar internasional dan mampu bersaing dalam dunia kerja global, maka diperlukan perpustakaan yang memiliki standar internasional. Seluruh kegiatan di perpustakaan yang berstandar World Class University Library (WCUL) akan lebih mudah bila dengan bantuan
Information Technology (IT), juga dengan biaya untuk pengelolaan yang memadai (Puspitasari \& Anawati, 2016). WCUL memiliki parameter-parameter penilaian, dimana parameter tersebut dapat digunakan sebagai tolak ukur apakah suatu perpustakaan di perguruan tinggi telah memenuhi standar WCUL. Informasi lebih lanjut mengenai parameter tersebut adalah pada jurnal berikut (Puspitasari \& Anawati, 2016).

ITS sebagai salah satu perguruan tinggi ternama dan terkemuka di Indonesia memiliki potensi yang sangat besar untuk menjadi salah satu perguruan yang memiliki reputasi internasional (standar internasional) seperti world class university. Sebagai perguruan tinggi 
terkemuka, ITS telah memiliki sejumlah syarat yang memungkinkan untuk menjadi world class university. Syarat itu antara lain kualitas dan kuantitas sumber daya manusia yang sangat memadai. Tentu saja syarat itu belum cukup dan masih dibutuhkan sejumlah syarat lainnya, seperti dukungan ketersediaan kurikulum yang bertaraf internasional, laboratorium yang standar, perpustakaan yang representatif dan fasilitas pendidikan lainnya.

Untuk menunjang perkembangan perpustakaan di ITS, setidaknya terdapat lima faktor teknologi yang berpengaruh. Pertama, dominasi penggunaan informasi yang berbasis online, hal ini akan juga terkait dengan pengadaan infrastruktur informasi dan pengembangan staf. Kedua, teknologi berubah secara terus menerus dan perubahan teknologi itu berlangsung cepat. Faktor tersebut membutuhkan investasi untuk mengikuti perkembangan dan mengatasi segala perubahan yang akan terjadi. Ketiga, kemampuan dan keterampilan mahasiswa makin meningkat dalam penggunaan komputer (computer literate), sehingga perpustakaan ITS harus memiliki tenaga ahli TI dan sumber daya lainnya untuk memenuhi kebutuhan mahasiswa. Keempat, integrasi proses pengajaran dengan teknologi multimedia, sehingga mengharuskan ITS melibatkan staf IT untuk mendukung ketersediaan pengajaran yang berbasis teknologi itu. Terakhir, adanya peningkatan pelayanan kepada pengguna seperti penambahan koleksi, jam buka layanan, fasilitas dan pustakawan yang menjadi tolok ukur dalam mempengaruhi jumlah pengguna perpustakaan.

Dalam pelaksanaan layanannya perpustakaan ITS menggunakan IT yang dapat mendukung kecepatan, kemudahan dan kenyamanan layanan perpustakaan. Penerapan layanan digital (http://library.its.ac.id/, http:// library.its.ac.id/opac/, http://repository.its.ac.id/, digilib. its.ac.id) adalah langkah mengintegrasikan teknologi informasi dengan misi perpustakaan. Untuk mencapai tujuan tersebut diperlukan suatu perencanaan dan implementasi teknologi informasi yang selaras dengan perencanaan dan strategi bisnis perpustakaan yang telah didefinisikan. Penerapan Teknologi Informasi yang selaras dengan tujuan perpustakaan tersebut akan tercapai apabila didukung oleh sistem tata kelola yang baik yang dimulai dari tahap perencanaan, implementasi dan evaluasi.

Pada penelitian ini, dilakukan pengukuran tingkat kematangan layanan pengguna perpustakaan berbasis Teknologi Informasi (TI). Hal ini bertujuan untuk memperoleh analisa dan gambaran dari tingkat kematangan layanan pengguna perpustakaan tersebut. Selanjutnya hasil analisa dan gambaran tersebut digunakan untuk menyusun usulan rekomendasi layanan perpustakaan di Institut Teknologi Sepuluh November Surabaya (ITS) yang berbasis teknologi informasi (TI) dengan menggunakan framework COBIT. Penelitian ini juga dilakukan untuk mendukung visi dan misi dari perpustakaan ITS dalam menjadi World Class University Library.

\section{TINJAUAN PUSTAKA \\ COBIT}

Control Objectives for Information and related Technology atau biasa disebut COBIT adalah sebuah kerangka kerja mengenai tata kelola teknologi informasi yang menyediakan praktik antara domain dan proses, serta menyajikan kegiatan yang struktur yang logis dan mudah diatur. Untuk dapat memahami kerangka kerja COBIT, perlu diketahui bahwa COBIT mempunyai karakteristik utama. Adapun karakteristik utama dari kerangka kerja COBIT adalah fokus pada bisnis, orientasi pada proses, berbasis kontrol dan dikendalikan oleh pengukuran. Informasi lebih lanjut mengenai COBIT dapat diakses pada link berikut (ISACA, 2017).

\section{LIBQUAL}

LibQual merupakan instrumen survei kualitas layanan yang dikembangkan oleh the Association of Research Libraries (ARL) dengan Texas A\&M University. LibQual merupakan survei untuk mengukur persepsi pemustaka atas layanan yang diberikan dan membantu perpustakaan mengidentifikasi layanan mana yang memerlukan perbaikan dengan tujuan utama untuk memperbaiki layanan kepada pemustaka. LibQual merupakan suatu metode yang digunakan oleh perpustakaan untuk mengumpulkan, mencari, memahami, dan menanggapi opini pemustakanya terhadap kualitas pelayanan yang diberikan (Nurkertamanda 2009). LibQual dikategorikan dalam tiga dimensi yaitu: Affect of Service yaitu kemampuan, sikap dan mental pustakawan dan petugas perpustakaan dalam melayani pengguna (meliputi: assurance, empathy, responsiveness, dan reliability), Information Access yaitu meliputi ketersediaan koleksi, kekuatan koleksi yang dimiliki, kemudahan mengakses, navigasi yang mudah, peralatan, timeliness yaitu kecepatan untuk mendapatkan informasi, kenyamanan dan kepercayaan diri, Library as Place yaitu perpustakaan sebagai sebuah tempat. Berkaitan dengan keampuhan perpustakaan memenuhi harapan pengguna dalam penyediaan fasilitas. 


\section{PROFIL UMUM PERPUSTAKAAN ITS}

Perpustakaan ITS memiliki visi yaitu: menjadi pusat sumber belajar (Learning Resource Center) berstandar internasional yang mendukung secara aktif pelaksanaan Tri Dharma Perguruan Tinggi ITS. Pengusulan penelitian ini juga bertujuan untuk mendukung visi dari perpustakaan ITS tersebut. Informasi lebih lanjut mengenai perpustakaan ITS dapat diakses pada url berikut http://library.its.ac.id/.

\section{WCUL}

World Class University Library (WCUL) adalah menjadi bagian dari perpustakaan-perpustakaan kelas dunia yang sudah memenuhi proses kualifikasi tertentu atas dasar pengakuan internasional (Salumbi).

\section{METODOLOGI}

Gambar 1 menunjukkan metodologi penelitian yang digunakan. Pada tahap pertama dilakukan studi lapangan. Tahap ini terdiri dari proses untuk menelaah dokumen dan studi literatur yang berhubungan dengan penelitian ini. Selanjutnya berdasarkan hasil studi lapangan tersebut, akan dilakukan pemilihan kerangka kerja. Dalam penelitian ini metode LibQual, COBIT, dan WCUL digunakan sebagai kerangka kerja yang menjadi dasar penilaian. Setelah melakukan perancangan kerangka kerja, maka tahap selanjutnya adalah pengumpulan data. Data dikumpulkan melakukan wawancara, kuesioner dan data sekunder.

Data dari hasil penyebaran kuesioner dan wawancara akan diolah dan dianalisa. Sehingga dapat diketahui tingkat kematangan dari kualitas pelayanan di perpustakaan ITS saat ini. Selanjutnya tingkat kematangan tersebut akan dibandingkan dengan indikator pada standar WCUL sebagai standar acuan dan harapan perpustakaan ITS kedepannya. Perbandingan ini menghasilkan analisa kesenjangan. Dimana analisa ini kemudian digunakan untuk merumuskan rekomendasi untuk perbaikan kualitas pelayanan di perpustakaan ITS kedepannya untuk sesuai dengan standar WCUL tersebut.

\section{HASIL DAN PEMBAHASAN}

Responden penelitian ini terdiri dari pustakawan atau pengelolaan yang mengurusi manajemen perpustakaan ITS, pengguna perpustakaan ITS yaitu mahasiswa, dosen, maupun tenaga pendidik di ITS.

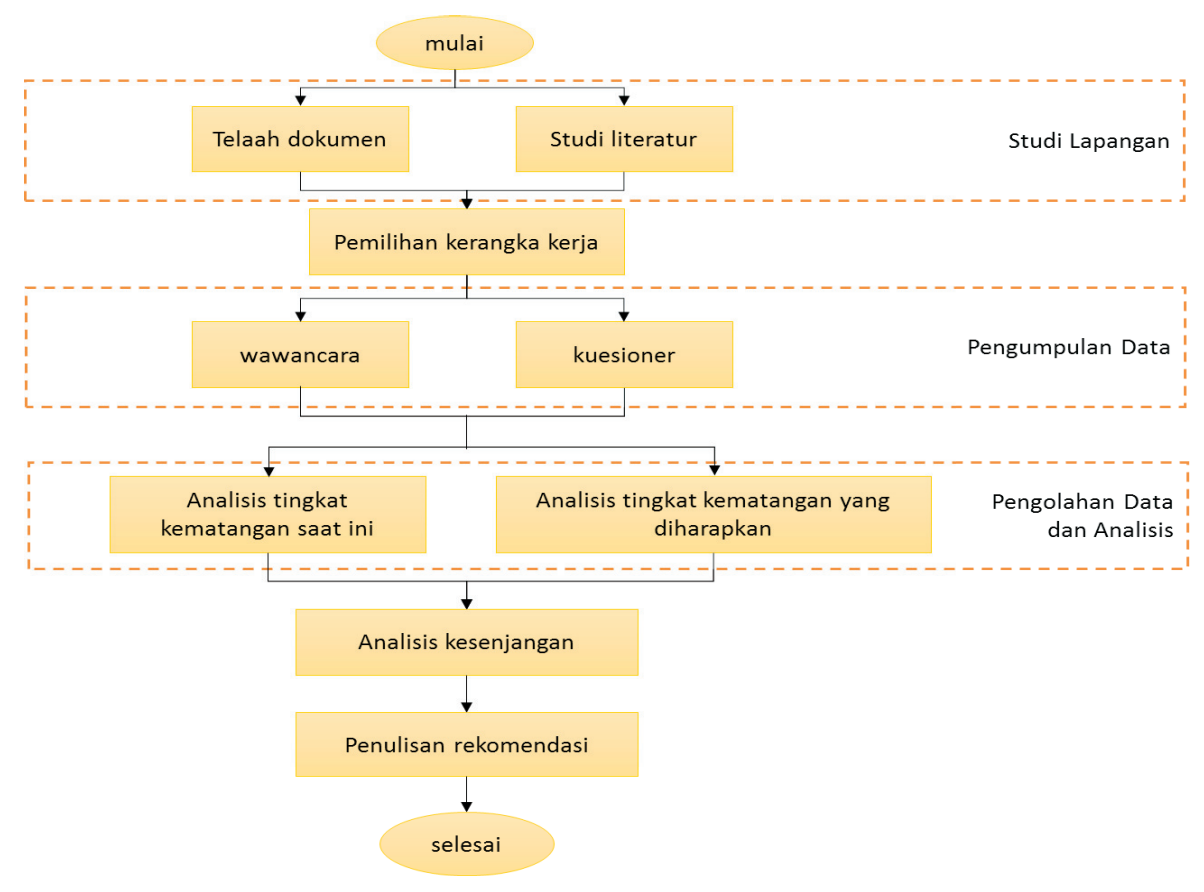

Gambar 1. Metode Penelitian 
Teknik penggalian data dilakukan dengan penyebaran kuesioner, wawancara dan observasi. Pertanyaan/ pernyataan dari kuesioner dan wawancara diturunkan dari indikator pada kerangka kerja COBIT dan LibQual. Adapun tahapan dari penelitian ini adalah sebagai berikut dalam Gambar 1

\section{Identifikasi Bisnis Strategi dengan IT Goals.}

Proses identifikasi awal adalah memetakan tujuan perpustakaan ITS sesuai dengan tujuan bisnis yang terdapat pada COBIT. Tujuan bisnis yang digunakan dalam penelitian yaitu misi yang terkait dengan layanan perpustakaan ITS. Hasil pemetaan yang didapat yaitu:

\section{Identifikasi Proses TI COBIT}

Proses ini dilakukan dengan cara melihat hasil pemetaan sebelumnya yaitu pemetaan dari tujuan bisnis ke tujuan TI COBIT. Setelah diperoleh tujuan TI COBIT, selanjutnya tujuan tersebut dipetakan pada proses-proses yang sesuai dengan proses bisnis perpustakaan ITS.

Tabel 1. Pemetaan Tujuan Bisnis Perpustakaan ITS dan Tujuan Bisnis Cobit

\begin{tabular}{lcc}
\hline \multicolumn{1}{c}{ Tujuan Bisnis Perpustakaan ITS } & Tujuan Bisnis COBIT & Tujuan Bisnis TI \\
\hline $\begin{array}{l}\text { Menyediakan layanan prima berorientasi } \\
\text { pemustaka berbasis teknologi informasi dan } \\
\text { komunikasi terkini (Misi 2) }\end{array}$ & Improve Customer Orientation and Service & 3,23 \\
$\begin{array}{l}\text { Meningkatkan standar mutu layanan } \\
\text { perpustakaan (Misi 4) }\end{array}$ & Establish Service Continuity and Availability & 10, 16, 22, 23 \\
\hline
\end{tabular}

Tabel 2. Hasil Pemetaan Tujuan pada Daftar Proses Berdasarkan Cobit 4.1.

\begin{tabular}{clc}
\hline & \multicolumn{1}{c}{ IT Business Goal } & IT Goals \\
\hline 3 & Ensure satisfaction of end users with service offerings and service levels & PO8, AI4, DS1, DS2, \\
10 & Ensure mutual satisfaction of third-party relationships & DS7,DS8,DS10,DS13 \\
16 & Reduce solution and service delivery defects and reworks & DS2 \\
22 & Ensure minimum business impact in the event of an IT service disruption or change & AI4, AI6, AI7, DS10 \\
23 & Make sure that IT service are available as require & DS3, DS4,DS8, DS13 \\
\hline
\end{tabular}

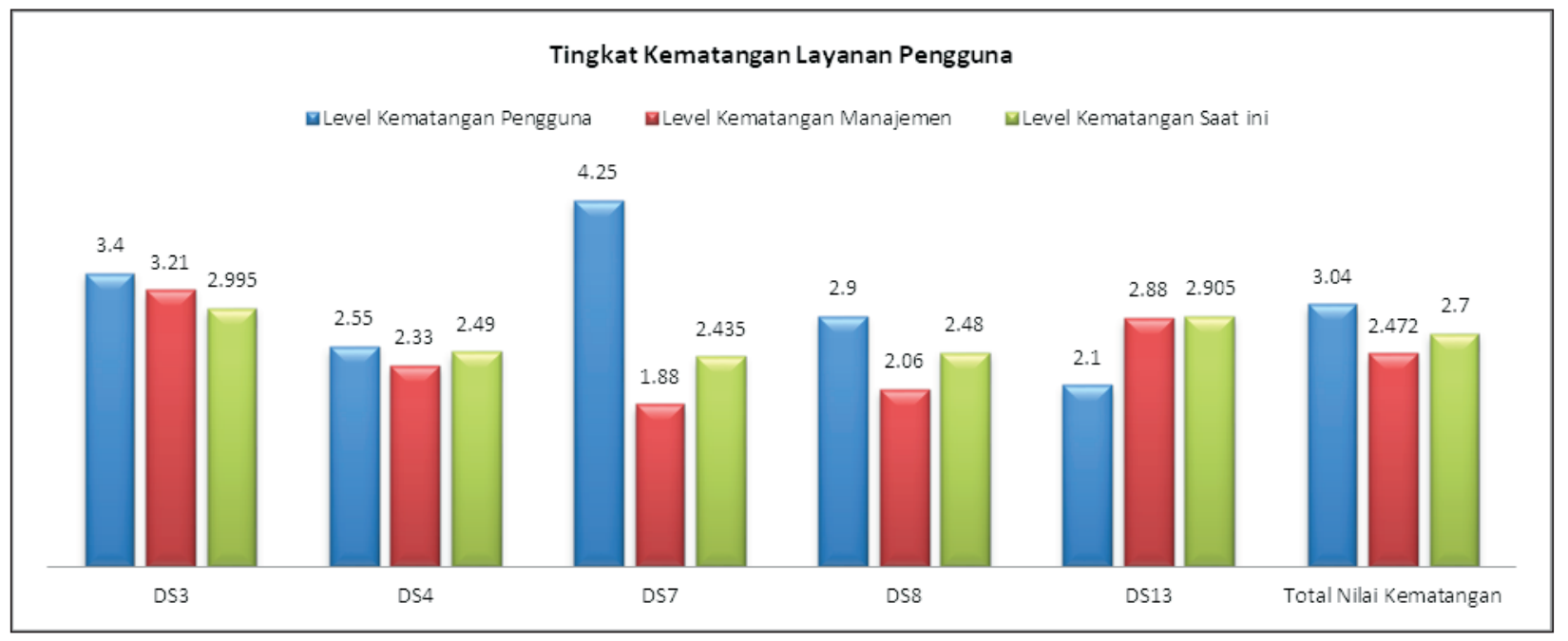

Gambar 2. Grafik Tingkat Kematangan Layanan Perpustakaan ITS 
Proses bisnis ini diturunkan dari tabel IT Process COBIT 4.1. Hasil pemetaan ini ditunjukkan pada Tabel 2.

Berdasarkan tujuan bisnis di atas, proses TI difokuskan pada domain Delivery and Support (DS), yaitu: DS3: Mengelola kinerja dan kapasitas, DS4: Memastikan layanan yang berkelanjutan, DS7: Mendidik dan melatih pengguna, DS8: Mengelola service desk dan insiden, DS13: Mengelola operasi.

\section{Penilaian dan Pengukuran Tingkat Kematangan}

Perhitungan tingkat kematangan dari kepuasan pengguna perpustakaan diolah berdasarkan hasil penyebaran kuesioner kepada pengguna. Kuesioner yang digunakan untuk pengumpulan data dirancang berdasarkan indikator-indikator dari domain delivery and support COBIT 4.1 yang terpilih (DS3, DS4, DS7, DS8, DS13), metode libqual yang dikerucutkan pada dimensi affect of service dan information control yang fokus pada kualitas dan akses informasi yang bertujuan

Tabel 3. Rata-Rata Tingkat Kematangan Layanan Pengguna

\begin{tabular}{clc}
\hline Domain & \multicolumn{1}{c}{ Keterangan } & $\begin{array}{c}\text { Tingkat } \\
\text { Kematangan } \\
\text { Saat ini }\end{array}$ \\
\hline DS3 & Mengatur kinerja dan kapasitas & 2.995 \\
DS4 & $\begin{array}{l}\text { Menjamin keberlangsungan } \\
\text { layanan }\end{array}$ & 2.49 \\
DS7 & $\begin{array}{l}\text { Mengedukasi dan melatih } \\
\text { pengguna }\end{array}$ & 2.435 \\
DS8 & $\begin{array}{l}\text { Mengelola service desk dan } \\
\text { masalah }\end{array}$ & 2.48 \\
DS13 & Mengatur operasional & 2.905 \\
\hline \multicolumn{2}{l}{ Total Nilai Kematangan } \\
\hline
\end{tabular}

untuk mengetahui kepuasan dari para pengguna yaitu mahasiswa dan dosen tentang segala sesuatu yang berhubungan dengan layanan pengguna yang saat ini sudah berjalan di lingkungan perpustakaan ITS.

Perhitungan tingkat kematangan dari manajemen dilakukan dengan memanfaatkan sebuah aplikasi dalam bentuk kuesioner yang terdapat pada Implementing and Continually Improving IT Governance-Supplemental Tools and Material dan wawancara mendalam terkait pencapaian perpustakaan ITS terhadap kriteria dari world class university library dan layanan pengguna yang terkait domain delivery and support COBIT.

Hasil pengolahan kuesioner yang sudah disebarkan kepada mahasiswa dan kuesioner yang diberikan kepada pihak management, dapat digambarkan dengan Tabel 3 dan Gambar 2. Berdasarkan analisa yang dilakukan maka dapat diambil kesimpulan rata-rata perhitungan nilai domain DS3, DS4, DS7, DS8 dan DS13 dalam tata kelola layanan pengguna berbasis teknologi informasi berada pada tingkat kematangan sebesar 2.7 dari skala $0-5$.

\section{Analisa Kesenjangan (Gap Analysis)}

Setelah mengetahui kondisi sekarang didapat nilai tingkat kematangan sebesar 2.7. Jika dibandingkan dengan kondisi tingkat kematangan yang diharapkan yaitu 4 , maka perpustakaan masih memerlukan banyak perbaikan dalam bidang pelayanannya. Tingkat kematangan yang diharapkan ditentukan dengan melihat faktor berikut:

Tabel 4. Perbandingan Tingkat Kematangan di Perpustakaan ITS

\begin{tabular}{cccc}
\hline \multirow{2}{*}{ Domain } & \multicolumn{3}{c}{ Tingkat Kematangan } \\
\cline { 2 - 4 } & Sekarang & Harapan & Kesenjangan \\
\hline DS & 2.66 & 4 & $4-2.7=1.3$ \\
\hline
\end{tabular}

Tabel 5. Temuan, Resiko, dan Rekomendasi pada Indikator Strategy Alignment

\begin{tabular}{|c|c|c|}
\hline Temuan & Resiko & Rekomendasi \\
\hline $\begin{array}{l}\text { Perpustakaan belum } \\
\text { menerapkan secara } \\
\text { menyeluruh sistem informasi } \\
\text { di setiap unit layanan }\end{array}$ & $\begin{array}{l}\text { Pekerjaan pengelola kurang } \\
\text { optimal karena sistem masih } \\
\text { manual }\end{array}$ & $\begin{array}{l}\text { Merencanakan pembuatan aplikasi baru untuk } \\
\text { pelayanan multimedia, layanan teknis }\end{array}$ \\
\hline $\begin{array}{l}\text { Perhatian terhadap } \\
\text { pengembangan sistem } \\
\text { informasi (OPAC, SPITS, } \\
\text { repository) yang ada masih } \\
\text { kurang }\end{array}$ & $\begin{array}{l}\text { Sistem informasi perpustakaan } \\
\text { ITS tidak sesuai dengan yang } \\
\text { diharapkan }\end{array}$ & $\begin{array}{l}\text { Merencanakan melakukan tindakan: } \\
\text { Merubah tampilan website perpustakaan ITS sesuai } \\
\text { tahapan. } \\
\text { Penyempurnaan SPITS sebagai katalog online dan } \\
\text { sebagai portal perpustakaan digital, } \\
\text { Evaluasi usability terhadap aplikasi local content }\end{array}$ \\
\hline
\end{tabular}


Visi dan misi serta tujuan dari perpustakaan ITS. Tabel 4 dan Gambar 3 menunjukkan tingkat kematangan di perpustakaan ITS pada saat ini yang dibandingkan dengan nilai kondisi kematangan yang diharapkan.

\section{Rekomendasi Pencapaian Tingkat Kematangan TI}

Berdasarkan hasil pengukuran didapatkan tingkat kematangan TI di perpustakaan ITS masih berada pada level 3. Nilai ini masih kurang dari standar nilai yang diinginkan di perpustakaan ITS yaitu level 4. Pada tingkat kematangan 4, diharapkan perpustakaan ITS dapat memanfaatkan TI yang ada dengan tepat guna.

Tabel 6. Temuan, Resiko, dan Rekomendasi pada Indikator Value Delivery

\begin{tabular}{|c|c|c|}
\hline Temuan & Resiko & Rekomendasi \\
\hline \multirow[t]{6}{*}{$\begin{array}{l}\text { Kurangnya pelatihan dan } \\
\text { pendidikan mengenai sistem } \\
\text { pelayanan perpustakaan, } \\
\text { Pendidikan dan pelatihan } \\
\text { yang telah berjalan selama ini } \\
\text { jarang diperbaharui isi materi. }\end{array}$} & \multirow[t]{6}{*}{$\begin{array}{l}\text { Pengguna } \\
\text { perpustakaan } \\
\text { tidak dapat } \\
\text { mendapatkan } \\
\text { informasi dengan } \\
\text { cepat dan tepat }\end{array}$} & $\begin{array}{l}\text { Memberikan pelatihan lebih banyak agar pengguna sistem } \\
\text { memahami cara kerja dari sistem pelayanan perpustakaan ITS } \\
\text { dengan baik. }\end{array}$ \\
\hline & & $\begin{array}{l}\text { Membangun e-resources class berbasis web untuk kemudahan } \\
\text { pengguna mendapatkan literasi informasi. }\end{array}$ \\
\hline & & $\begin{array}{l}\text { Materi pendidikan dan pelatihan mengenai sistem pelayanan } \\
\text { perpustakaan ITS seharusnya selalu diperbarui sesuai dengan } \\
\text { kebutuhan saat ini maupun untuk kebutuhan dimasa yang akan } \\
\text { datang. }\end{array}$ \\
\hline & & $\begin{array}{l}\text { Melakukan evaluasi proses pelatihan dan hasil pelatihan. Hasil } \\
\text { evaluasi ini harus menjadi masukan dalam menentukan jenis } \\
\text { pelatihan dan kurikulum pelatihan yang akan datang. }\end{array}$ \\
\hline & & $\begin{array}{l}\text { Diperlukan bimbingan pengguna lainnya seperti reference manager } \\
\text { (zotero atau mendeley) untuk penulisan karya ilmiah. }\end{array}$ \\
\hline & & $\begin{array}{l}\text { Meningkatkan kemampuan pustakawan tentang tata cara } \\
\text { menyampaikan materi sehingga materi yang diajarkan bisa } \\
\text { dipahami oleh pengguna }\end{array}$ \\
\hline \multirow{3}{*}{$\begin{array}{l}\text { Tidak adanya SOP untuk } \\
\text { mengatasi masalah/keluhan, } \\
\text { pengelola kurang proaktif } \\
\text { dan kurang mendukumentasi } \\
\text { terhadap masalah yang ada }\end{array}$} & \multirow{3}{*}{$\begin{array}{l}\text { Pengambilan } \\
\text { keputusan } \\
\text { menjadi } \\
\text { terlambat jika ada } \\
\text { permasalahan }\end{array}$} & $\begin{array}{l}\text { Pembuatan SOP untuk mengatasi permasalahan mulai dari } \\
\text { identifikasi hingga penyelesaian masalah. }\end{array}$ \\
\hline & & $\begin{array}{l}\text { Mendokumentasikan semua masalah yang terselesaikan dan } \\
\text { mencatat akar penyebab masalah. }\end{array}$ \\
\hline & & $\begin{array}{l}\text { Membuat laporan aktivitas service desk, sehingga kinerja service } \\
\text { desk dan waktu respon layanan menjadi terpantau dan terukur, } \\
\text { sehingga permasalahan yang seringkali terjadi tidak terulang }\end{array}$ \\
\hline $\begin{array}{l}\text { Layanan service desk belum } \\
\text { diketahui oleh pengguna }\end{array}$ & $\begin{array}{l}\text { Layanan service } \\
\text { desk tidak } \\
\text { berfungsi dengan } \\
\text { baik sehingga } \\
\text { tidak optimal }\end{array}$ & $\begin{array}{l}\text { Menetapkan fungsi bagian penerima layanan atau service desk, } \\
\text { sehingga pengguna tahu dimana tempat menyampaikan masalah } \\
\text { yang dihadapinya dan mensosialisasikannya }\end{array}$ \\
\hline Kurangnya Jam Pelayanan & $\begin{array}{l}\text { Pengguna } \\
\text { kekurangan } \\
\text { informasi }\end{array}$ & $\begin{array}{l}\text { Untuk memungkinkan pengguna bisa mengakses informasi } \\
\text { perpustakaan setiap saat maka perlu adanya penambahan jam } \\
\text { layanan, melakukan inovasi dengan memanfaatkan teknologi yang } \\
\text { ada. }\end{array}$ \\
\hline
\end{tabular}


Tabel 7. Temuan, Resiko, dan Rekomendasi pada Indikator Resource Management

\begin{tabular}{|c|c|c|}
\hline Temuan & Resiko & Rekomendasi \\
\hline $\begin{array}{l}\text { Kurangnya staf pustakawan } \\
\text { untuk mengelola kegiatan } \\
\text { layanan dan staf IT terutama } \\
\text { untuk bagian pengembangan } \\
\text { aplikasi }\end{array}$ & $\begin{array}{l}\text { Pekerjaan yang } \\
\text { dibebankan menjadi } \\
\text { kurang maximal }\end{array}$ & $\begin{array}{l}\text { Merekrut SDM yang berpendidikan perpustakaan dan } \\
\text { IT. Meningkatkan pendidikan SDM yang ada dengan } \\
\text { memberikan kesempatan melakukan studi lanjut. } \\
\text { Peningkatan kompetensi pustakawan yang telah ada saat } \\
\text { seiring dengan perkembangan teknologi informasi. } \\
\text { Kekosongan posisi koordinator TIK harus segera dicarikan } \\
\text { orang yang benar-benar berkompeten di bidangnya, } \\
\text { memiliki pendidikan, pengalaman dan keterampilan di } \\
\text { bidang TIK sehingga pengembangan TIK di perpustakaan } \\
\text { bisa direncanakan dan dilaksanakan dengan baik. }\end{array}$ \\
\hline $\begin{array}{l}\text { Training SDM untuk } \\
\text { bidang IT masih kurang. } \\
\text { Perpustakaan fokus ke } \\
\text { kegiatan pengelolaan } \\
\text { perpustakaan }\end{array}$ & $\begin{array}{l}\text { Kemampuan pengelola } \\
\text { tidak bisa berkembang } \\
\text { sehingga perkembangan } \\
\text { IT terhambat }\end{array}$ & $\begin{array}{l}\text { Perpustakaan mengikutsertakan satu atau beberapa orang } \\
\text { staf TIK untuk mengikuti kursus terkait TIK terutama } \\
\text { pengembangan program/programmer, sehingga nantinya } \\
\text { perpustakaan akan memiliki programmer sendiri. }\end{array}$ \\
\hline $\begin{array}{l}\text { Pemenuhan kebutuhan } \\
\text { komputer dan peremajaan } \\
\text { komputer tidak bisa dipenuhi } \\
\text { dengan cepat }\end{array}$ & $\begin{array}{l}\text { Tugas pengelola menjadi } \\
\text { terlambat }\end{array}$ & $\begin{array}{l}\text { Penambahan dan pemeliharaan infrastruktur/komputer } \\
\text { harus ditingkatkan agar tidak mengganggu layanan sistem } \\
\text { informasi perpustakaan IT dan Menyediakan komputer } \\
\text { khusus untuk pengembangan sistem. }\end{array}$ \\
\hline $\begin{array}{l}\text { Kurangnya jumlah online } \\
\text { database dan akses terhadap } \\
\text { e-book dan jumlah koleksi } \\
\text { tercetak }\end{array}$ & $\begin{array}{l}\text { Kebutuhan informasi } \\
\text { pengguna tidak terpenuhi } \\
\text { dengan baik }\end{array}$ & $\begin{array}{l}\text { Penambahan koleksi e-resources sesuai kebutuhan } \\
\text { pengguna dan sosialisasi lebih gencar dilakukan } \\
\text { Meningkatkan jumlah koleksi tercetak yang sesuai dengan } \\
\text { subyek kebutuhan pengguna }\end{array}$ \\
\hline $\begin{array}{l}\text { Bandwith perpustakaan ITS } \\
\text { kurang dari } 80 \mathrm{MB}\end{array}$ & $\begin{array}{l}\text { Akses WiFi lambat } \\
\text { karena banyak yang } \\
\text { menggunakan }\end{array}$ & $\begin{array}{l}\text { Menambahkan bandwith Jaringan internet untuk sistem } \\
\text { layanan perpustakaan ITS. } \\
\text { Menyediakan/melanggan jaringan lain di luar jaringan ITS } \\
\text { sebagai alternati ketika jaringan ITS mengalami gangguan/ } \\
\text { pemadaman listrik, agar proses layanan sistem informasi } \\
\text { perpustakaan ITS tetap berjalan dengan lancar dan tidak } \\
\text { mengalami hambatan. }\end{array}$ \\
\hline $\begin{array}{l}\text { Kurangnya ruangan untuk } \\
\text { berdiskusi dan belajar khusus }\end{array}$ & $\begin{array}{l}\text { Pengguna merasa tidak } \\
\text { nyaman dalam melakukan } \\
\text { research }\end{array}$ & $\begin{array}{l}\text { Penambahan ruang diskusi dan study carrel untuk } \\
\text { mahasiswa pasca dan peneliti }\end{array}$ \\
\hline
\end{tabular}

Tabel 8. Temuan, Resiko, dan Rekomendasi pada Indikator Risk Management

\begin{tabular}{lll}
\hline \multicolumn{1}{c}{ Temuan } & \multicolumn{1}{c}{ Resiko } & \multicolumn{1}{c}{ Rekomendasi } \\
\hline $\begin{array}{l}\text { Sistem keamanan perpustakaan } \\
\text { ITS masih lemah kurang aman } \\
\text { pentuk penyimpanan data-data }\end{array}$ & $\begin{array}{l}\text { Data bisa disalahgunakan, hilang } \\
\text { atau dicuri }\end{array}$ & $\begin{array}{l}\text { Perlu di lakukan sistem pengamanan jaringan, } \\
\text { hanya orang-orang tertentu yang bisa melakukan } \\
\text { akses }\end{array}$ \\
$\begin{array}{l}\text { Perpustakaan ITS hanya } \\
\text { memiliki satu server dan } \\
\text { dititipkan di DPTSI }\end{array}$ & $\begin{array}{l}\text { Kalau ada masalah dengan } \\
\text { sistem pelayanannya lebih lama } \\
\text { tidak bisa langsung eksekusi } \\
\text { tergantung perfoma DPTSI }\end{array}$ & $\begin{array}{l}\text { Mengelola Server sendiri sehingga bisa } \\
\text { mengevaluasi dokumentasi risiko yang pernah } \\
\text { dihadapi }\end{array}$ \\
\hline
\end{tabular}


Tabel 9. Temuan, Resiko, dan Rekomendasi pada Indikator Performance Measurement

\begin{tabular}{lll}
\hline \multicolumn{1}{c}{ Temuan } & \multicolumn{1}{c}{ Resiko } & \multicolumn{1}{c}{ Rekomendasi } \\
\hline Aturan dan dokumen & Kinerja perpustakaan tidak efektif & Perpustakaan ITS menetapkan standar kontrol IT yang \\
terkait IT belum & dan efesien. Kemungkinan terjadi & telah baku seperti: \\
maksimal dan & penyimpangan terhadap strategi & COBIT, \\
belum ada standar & yang ditetapkan & ITIL \\
pengukuran IT. & & dan ISO \\
& & Membentuk tim untuk memantau kegiatan dan kinerja \\
& & terkait IT di perpustakaan ITS \\
\hline
\end{tabular}

\section{KESIMPULAN}

1. Perpustakaan ITS direkomendasikan untuk membuat standar prosedur kerja (SOP) dan melakukan pengawasan dan pemeriksaan proses layanan terkait TI.

2. Perpustakaan ITS perlu menyamakan visi dan misinya menuju internasionalisasi dengan meningkatkan sarana dan prasarana perpustakaan sesuai standar WCUL.

\section{DAFTAR PUSTAKA}

A. Wijaya, "Evaluasi Tingkat Kematangan Pengelolaan Data Sistem Informasi Administrasi Kependudukan Menggunakan Kerangka Kerja Cobit di Kota Pariaman," Padang, 2
I.D. Hartanto and A. Tjahyanto, "Analisa Kesenjangan Tata Kelola Teknologi Informasi untuk Proses Pengelolaan Data Menggunakan COBIT (Studi Kasus Badan Pemeriksa Keuangan Republik Indonesia),' in Program Studi Magister Manajemen Teknologi Bidang Keahlian Manajemen Teknologi Informasi Institut Teknologi Sepuluh November, Surabaya, 2010.

I.G. Institute, COBIT 4.1, Rolling Meadows, 2007.

N. Hasanah, "World Class University Library"

S. Adi, "Gap Analysis (Analisa Kesenjangan)," 28 July 2015. [Online]. Available: ttp://sis.binus.ac.id/2015/07/28/gapanalysis-analisa-kesenjangan/. [Accessed 24 November 2016].

Salmubi, "Perpustakaan Universitas Indonesia menuju World Class University Library," Jakarta. 